\title{
Digital Educational Technology in a Higher Education Institution
}

\author{
V.B. Dzobelova \\ North Ossetian State University \\ named after Kosta Levanovich Khetagurov \\ Vladikavkaz, Russia \\ dzobelova@mail.ru
}

O.V. Cherkasova

National research Mordovian state University. N. P. Ogarev

Saransk, Russia

cherov2007@yandex.ru

\author{
S.L. Yablochnikov \\ Moscow Technical University of Communication and \\ Informatics \\ Moscow, Russia \\ vvkfek@mail.ru
}

\section{S.V. Gerasimov}

St. Petersburg state University of Economics

Saint-Petersburg, Russia

votje82@mail.ru

\begin{abstract}
Digitization is becoming a global trend in the development of society. It's a process that is based on the conversion of information into digital form and leads to an increase in the efficiency of the economy and an improvement in the quality of life. Due to digitization, new conditions for the development of the industry are created, the formats of production and consumption are changed, ideas about professionalism, a culture of behavior and communications, and ways of perception and thinking are changing. There are new requirements for the basic competencies of specialists in the labor market. An urgent task is the digitization of education. The main objective of the Russian policy in the field of education is quality assurance based on maintaining its fundamental nature and meeting current and future needs of the person, society and the state. The organization of the educational process in higher education institution depends, first of all, on the administration of the institution. The presence or absence of a specific educational strategy largely determines the principles of the educational process organization, its subsequent support and expected results at the "output". The basic principles of the formation of the educational strategy are accessibility, quality and mobility, and the current federal state educational standards act as the basis. Each university has its system of practical implementation of internal mechanisms for guaranteeing the quality of education, and each system is built according to its principles. The article is devoted to the use of digital technologies in higher education. The determining factors for the successful process of education digitization in Russia are highlighted in the article.
\end{abstract}

Keywords: digitization, digital technologies, digital education, elearning, distant education

\section{INTRODUCTION}

In modern socio-economic conditions and existing market competition, the demand for human capital is increasing [1].

The labor market sets competitive conditions for young specialists - graduates of higher educational institutions since a modern employer needs worker with a full range of expertise, knowledge and skills in the area of their labor application. But also, job-seekers are required to have a spacious mind and fast orientation in the rapidly changing modern information space, the ability to analyze and create new knowledge, the readiness to adopt new methods and technologies, the possession of extensive knowledge that goes beyond the narrow specialization obtained in the direction of training, and also the readiness to continue and improve their education constantly. All this requires modern approaches to the formation of professional competence and to the organization of the educational process in the system of higher professional education. Modern trends in the development and application of information technologies (performed in such phenomena as general computerization, Internet access, the development of social networks, mobile Internet, augmented reality, virtual reality) give a qualitatively different level of human interaction with digital technologies, which requires updated approaches in psychological research methods in this area.

The development of digital technologies has a significant impact on all spheres of modern society`s life, transforming the most common foundations of human being and conscious experience. 


\section{METHODOLOGY}

In July 2017, the Government of the Russian Federation approved the program Digital Economy of the Russian Federation. A federal project "Digital educational environment" is being developed. It is aimed at the formation of a secure digital educational space that meets the requirements and needs of the Digital Economy and society as a whole.

Under the influence of digitization, modern education receives a powerful impetus to improve its content, forms, methods, technologies. This circumstance contributes to the rethinking of the role of the teacher, which forms independence, initiative, creative style of students' activity; high motivation for the adoption of information corresponding to the needs, interests, styles, and strategies of the subject. Network remote form and autonomous distant form of learning allow overcoming physical, spatial and time constraints, which can make it difficult to get an education for a person [2]

Today, digital technologies are no longer just an additional instrument, but also a necessity, need and condition for the existence of a modern person [2]. It affects directly higher education, which at the present stage is being reconstructed based on the application of Bologna processes and competency-based approaches in education, as an important component of these processes. The concept of competency penetrates various areas of society from primary and secondary education to higher education, to professional activity and labor relations. The formation of educational competence is considered as the main goal and, at the same time, an assessment of the level and quality of students' education. An integral part of competence is personal competency, which includes creativity among other things.

All this indicates that at the development of modern educational programs and methods (which require considering the competency-based approach and the active use of digital technologies, interactive, distance education) one should carefully take into account many psychological aspects, both the content of the educational process and the individual characteristics of students' personalities.

Ensuring high-quality training of specialists is achieved by a system of external and internal mechanisms of quality assurance [5]. Along with the state accreditation procedures of the university and educational programs, the university develops and implements its own educational standards, certification and self-certification procedures of its departments, development programs, quality management systems based, among other things, on the requirements of the international standard ISO 9001:2000, total quality management (TQM) et al. [5].

According to some authors, the system of total quality management is a method of production management, including products of intellectual activity in higher educational institutions [5]. The introduction of this model requires clarification of goals, adjustment of the mission of an educational organization, changes in the organizational structure and methods of university management, the introduction of new elements into the corporate culture, the realization of sociotechnical solutions and many others.

Nowadays, it is almost impossible to imagine the activities of any educational organization without appropriate information support [5]. The organization posts information on its activities on its information portal, as well as on the websites of federal operators in the field of education. The procedure for university entrance should be accompanied by ratings of applicants on the page of the educational organization on the Internet and at the same time, all the basic information about the applicant is already contained in the Federal Information System of State Final Examination (FIS SFE) and Enrollment database. In the learning process, federal bodies in the field of education monitor the movement of students of all forms and fundamentals of education. A national monitoring system for the training of specialists at all levels of education is being formed. We are already accustomed to the fact that without systematic information interaction, it is impossible to build work with executive authorities, the media, schools, departments within an educational organization, and finally, with students themselves. All of the above determined the need for the implementation of the educational process of information systems and software modules that allow continuously receiving and exchanging information about the implementation of educational programs, the movement of the contingent, pass rate and other parameters.

\section{ANALISYS}

Digitization of education reveals several problems that need to be solved.

We list the problems that arise when the use of digital technologies is meaningless. As it is known, many universities now use learning management such as Moodle, Blackboard, Desire2Learn and others. "The main disadvantages of the systems include the discrepancy with the specifics of the organization of the educational process in the higher school of the Russian Federation, the lack of Russian certificates for information protection" [8]. There are no general rules for the use of control systems, each university interprets them in its way. Often it appears that teachers carry out the classroom load and simultaneously fill in an electronic course, that takes a lot of time, which teachers have in lack under modern workloads.

Despite the apparent beauty and convenience of presentations at lectures, students themselves note that the lecturer's speech and synchronous recording of formulas and definitions on the board are easier to perceive. It seems that the lecturer speaking phrases written on slides make the lecture boring. Although, as an addition to the lecture material, the slides are not so bad. For example, at a lecture on biology about the structure of organisms, pictures and diagrams would be very appropriate. At lectures on mathematics and physics, a three-dimensional model on a computer looks more advantageous than chalk drawing on a blackboard. But after all, a person who gives lectures with the help of presentations, most likely, never listened to such lectures himself and hardly can imagine himself in the place of the listener. 
When writing tests, examination, a classroom and a teacher, which can ensure that students do not copy down, are still required. If the test is written outside the classroom, then there is no guarantee that it was passed by the student and not the person with the rank of professor it should be mentioned another problem regarding electronic courses. In personal interaction with students, the teacher can evaluate the level of students in this group, learning style. Sometimes within the same course, there are groups of students requiring a completely different approach to learning, not to mention students from different areas of training. Let's note "what" prevents the introduction of digital technologies into the educational process:

- the unwillingness of teachers to change regular teaching methods to new forms;

- lack of technical equipment at the university;

- the inability of teachers to work under new conditions;

- lack of a regulatory framework [9].

If one takes into consideration the average age of university lecturers, then the above reasons become obvious. The teaching staff of universities must be trained in the use of digital technologies, otherwise, they will have to wait until each lecturer has mastered new educational technologies by trial and error.

The development of open educational Internet resources such as Coursera, National Open University INTUIT, Lectorium, the Russian national platform for open education, create serious competition for classical education [10]. Thus, the transition from conservative teaching methods to new ones using digital technologies will undoubtedly be long and difficult. But the fact is that education in the modern world simply cannot be the same as 30 years ago. If each lecturer will take it reasonably, analyze and look for ways to solve problems, perhaps, then a new model of education, that will allow a graduate of a university to feel confident in the modern world, will be built.

\section{RESULTS}

In the context of serious differences in the structure and specialization of different universities, a single, uniform procedure of digitization of higher education is impossible. The development of digital education in different universities should be consistent with the specifics of universities and their students. Moreover, one should not forget that the development of digital education will further reinforce the trend towards differentiation and specialization of universities.

New formats of collaboration and training oriented to the student will require students to take greater responsibility for the quality of their education. Within the framework of digital education, the value of professors as "knowledge broadcaster" will decrease and their importance as people accompanying individual student learning will increase. Such changes in educational formats may require the development of new specific competencies by teachers, including those related to digital technologies.
It is not enough to digitize educational materials for successful digitization. The use of new media is only the initial condition for the further development of teaching, the criterion of estimation of which is its usefulness for the student. Innovations in the content and construction of training courses, organizational and structural changes in universities should bring real benefits to students.

Universities should be attended not so much to the advancement of technological innovations (such as the creation of their electronic resources and applications) as to the development of their educational programs at the expense of already existing infrastructure.

The determining factor for the success of the digitization of education is the university's strategy and not the available financial resources. Financial resources are usually necessary but not sufficient condition for the development of digital education. A key factor for the success and speed of the implementation of digital methods is whether they are included in the university's real strategy or implemented only as part of the "modernization" of the existing methods and organizational procedures.

A significant share in financing digital initiatives is external, non-university financing. It supposes not only advantages but also the risks of taking somebody`s goals in the digitization process.

External financing, however, creates isolated projects that are not built into the real strategy of university development. This is especially dangerous given the stagnating financing of the core business of the university and the increase of the dependence of universities on external project financing.

\section{CONCLUSION}

It is necessary to create financial incentives for the development of sustainable digital education added to the university's strategy, including the presence of digitization projects in sustainable targeted financing schemes [11].

We live in a time when the concentration of new digital technologies is greater than ever in all sectors of our lives [12]. These technologies are already capable of influencing the universities' activity. Many educational institutions on the territory of the Republic of North Ossetia-Alania strain after the introduction of digital education in the process of their activity. However, educational institutions have to be transformed significantly yet to realize the benefits of digitization and provide students with more opportunities.

The development of innovation technologies leads to high labor mobility within the global economy. Therefore, it is important to consider that not only knowledge exchange is necessary, but also the outflow of trainees and students is possible in cases where the level of national higher education does not meet international standards, as well as when graduates of higher educational institutions cannot find work in their specialty.

Innovation technologies now allow individual users to enter global markets. In the future, this may lead to the fact that workers will independently make the transition from the 
[5] P. Doucek and J. Hološka, "Digital economy and industry 4.0 IDIMT2019", Innovation and Transformation in a Digital World, 27th Interdisciplinary Information Management Talks (Sept. 4-6, 2019 Kutná Hora, Czech Republic), TRAUNER Druck GmbH and Co KG, Linz, 2019. pp. 33-39.

category of labor suppliers to the category of owners of a certain capital. Thus, even novice lawyers will be able to attract resources independently in the market and form their law firms that will interact with other users through platform systems.

In order to meet the new needs of the labor market, higher educational institutions should provide structured and quality education, which is likely to require a revision of the student curriculum and reduction of study hours in applied disciplines. At the same time, the students should develop the basics of conceptual design and entrepreneurship, as well as social behavior skills that can prepare students for independent activity as micro-entrepreneurs in the innovation economy.

The indisputable advantage of digital technologies is the ability to ensure that each person acquires new knowledge and competencies at any stage of professional development, which is very important in a rapidly changing world.

\section{REFERENCES}

[1] G. Abdrakhmanova, L. Gokhberg, and A. Sokolov, "Indicators of Information and Communication Technology", Encyclopedia of Information Science and Technology, 2017, Fourth Edition, Hershey, IGI Global, 2018.

[2] J. Basl, "Penetration of Industry 4.0 Principles into ERP Vendors' Products and Services - A Central European Study", Proceedings of the International Conference on Research and Practical Issues of Enterprise Information Systems, 2017. DOI: http://dx.doi.org/10.1007/978-3-31994845-4_8.

[3] J. Basl and P. Doucek, "A Metamodel for Evaluating Enterprise Readiness in the Context of Industry 4.0. Information", 10(3), 2019. DOI: http://dx.doi.org/10.3390/info10030089.

[4] O. Ena and G. Abdrakhmanova, "ICT through the prism of critical technologies", Foresight, 2017, vol. 19, no. 2, pp. 121-138.
[6] L. Gerlitz, "Design management as a domain of smart and sustainable enterprise: business modelling forinnovation and smart growth in Industry 4.0", Entrepreneurship and Sustainability, 2016, issues 3(3), pp. 244-268. DOI: https://doi.org/10.9770/jesi.2016.3.3(3)

[7] M. Ignatiev, E. Karlik, E. Iakovleva, and V. Platonov, "Linguocombinatorial model for diagnosing the state of human resources in the digital economy", In the book: Proceedings of 2018 17th Russian Scientific and Practical Conference on Planning and Teaching Engineering Staff for the Industrial and Economic Complex of the Region, PTES 2018, 17, pp. 201-204.

[8] A. Issa, B. Hatiboglu, A. Bildstein, and T. Bauernhansl, "Industrie 4.0 roadmap: Framework for digital transformation based on the concepts of capability maturity and alignment", Procedia CIRP, 72 (51st CIRP Conference on Manufacturing Systems), 2018, pp. 973-978. DOI:10.1016/j.procir.2018.03.151.

[9] L. Novák and P. Doucek, "Regulation of Cyber Security in the Banking Sector", Proceedings of the International Conference IDIMT-2017 Digitalization in Management, Society and Economy, 2017 [Electronic resource]. Available at: http://idimt.org/wpcontent/uploads/proceedings/IDIMT_proceedings_20 17.pdf

[10] A. Pavlíček, R. Novák, L. Böhmová, and S. Yabloschnikov, "Social media as a data source for human resources", IDIMT-2019, Innovation and Transformation in a Digital World, 27th Interdisciplinary Information Management Talks (Sept. 4-6, 2019), Kutná Hora, Czech Republic, TRAUNER Druck GmbH and Co KG, Linz, 2019, pp. 219228.

[11] P. Sladek and M. Maryska. "Internet of things in energy industry", In IDIMT-2017-Digitalization in Management, Society and Economy-25th Interdisciplinary Information Management Talks, Edited by Doucek Petr, Chroust Gerhard and Oškrdal Vaclav, Linz: Trauner Verlag Universität, 2017, pp. 411-18. ISBN 978-3-99062-119-6.

[12] "Science and Technology. Innovation", Information Society, 2017. 